\title{
Microstructure and high temperature 4-point bending creep of sol-gel derived mullite ceramics
}

\author{
Hrvoje Ivankovic $^{\mathrm{a}}$, Emilija Tkalcec ${ }^{\mathrm{a}, *}$, Ruediger Rein ${ }^{\mathrm{b}}$, Helmut Schmidt $^{\mathrm{b}}$ \\ ${ }^{a}$ Faculty of Chemical Engineering and Technology, University of Zagreb, 19 Marulicev trg, HR-10000 Zagreb, Croatia \\ ${ }^{\mathrm{b}}$ Institut fuer Neue Materialien, Im Stadtwald, Gebaeude 42, D-66123 Saarbruecken, Germany
}

\begin{abstract}
Four-point bending creep behavior of mullite ceramics with monomodal and bimodal distribution of grain sizes was studied in the temperature range of $1320-1400^{\circ} \mathrm{C}$ under the stresses between 40 and $160 \mathrm{MPa}$. Mullite ceramic with bimodal grain size distribution was prepared using aluminum nitrate nonahydrate as alumina precursor. When $\gamma-\mathrm{Al}_{2} \mathrm{O}_{3}$ or boehmite were used as alumina precursors, mullite grains are equiaxial with mean particle size of $0.6 \mu \mathrm{m}$ for the former and $1.3 \mu \mathrm{m}$ for the latter alumina precursor. The highest creep rate exhibited the sample with monomodal morphology and grains in size of $0.6 \mu \mathrm{m}$, which is about one order of magnitude greater than that for the monomodal morphology but with grains in size of $1.3 \mu \mathrm{m}$. The highest activation energy for creep $(Q=742 \pm 33 \mathrm{~kJ} / \mathrm{mol})$ exhibits mullite with equiaxial grains of $1.3 \mu \mathrm{m}$, whereas for sample with smaller equiaxial grains the activation energy is much smaller and similar to mullite ceramics with bimodal grain morphology. Intergranular fracture is predominant near the tension surface, while transgranular more planar fracture is predominant near the compression surface zone.
\end{abstract}

Keywords: Mullite; Creep; Microstructure-final; Morphology

\section{Introduction}

Mullite is a promising candidate for advanced structural and functional ceramics because of its good thermomechanical properties, excellent creep resistance and good chemical and oxidation resistance. ${ }^{1}$ Creep of mullite has been investigated for the last three decades. Works have been performed in bending, ${ }^{2-13}$ in compression ${ }^{11,14-19}$ and in tension. ${ }^{11}$ Materials with different microstructures and compositions ranging from 67 to $82 \mathrm{wt}$. $\%$ of alumina and a wide range of activation energies ( $Q \sim 357-1051 \mathrm{~kJ} / \mathrm{mol})$, stress exponents $(n \sim 0.2-2.7)$ and grain size exponents $(p \sim 1-3.7)$ have been characterized in experiments from 0.2 to $300 \mathrm{MPa}$ and temperatures from 1100 to $1500{ }^{\circ} \mathrm{C}$. There is no universally accepted opinion about the mechanism of the creep. In general, grain boundary sliding (GBS) is considered to

\footnotetext{
* Corresponding author. Tel.: +385 14597 219; fax: +385 14597250

E-mail address: etkalcec@fkit.hr (E. Tkalcec).
}

be the main deformation mechanism, but some authors suggest that the strain rates are controlled by viscous flow of amorphous grain boundary phases, another by pure diffusion. Solution-precipitation and/or cavitation were also suggested as processes accompanying the dominant process. It is generally agreed that broad range of reported creep parameters are due to differences in experimental conditions: loading arrangement, temperature and stress as well as in microstructure and composition of the studied materials.

The goal of this work was to present the bending creep results of sol-gel derived mullite ceramics with the same stoichiometric 3:2 mullite composition but with different microstructure, and different size and distribution of mullite grains, which was attained by using various alumina precursors. Tetraetoxysilane (TEOS) was used as a source of silica, and aluminum nitrate nonahydrate, $\left(\mathrm{Al}\left(\mathrm{NO}_{3}\right)_{3} \cdot 9 \mathrm{H}_{2} \mathrm{O}\right)$, $\gamma-\mathrm{Al}_{2} \mathrm{O}_{3}$ and boehmite $(\gamma-\mathrm{AlOOH})$, respectively, were used as the sources of alumina component. 


\section{Experimental procedure}

\subsection{Sample preparation}

Four mullite precursors with stoichiometric 3:2 mullite composition $\left(3 \mathrm{Al}_{2} \mathrm{O}_{3} \cdot 2 \mathrm{SiO}_{2}\right)$ but with different level of mixing, consequently with different microstructure, were prepared as follows. Gel W was prepared by dissolving $\mathrm{Al}\left(\mathrm{NO}_{3}\right)_{3} \cdot 9 \mathrm{H}_{2} \mathrm{O}$ in water (nitrate/water molar ratio equals 1:32). The solution was stirred and refluxed at $60^{\circ} \mathrm{C}$ overnight. Tetraethoxysilane (TEOS, Fluka >98\%) previously mixed with ethanol (with TEOS/ethanol molar ratio of 1/4) was added dropwise to the nitrate solution. The mixture was heated at $60{ }^{\circ} \mathrm{C}$ under reflux condition until gelation. First step in the preparation of gel M1 was the same as in gel W, but, after mixing nitrate solution and TEOS, the stirring was continued for next $12 \mathrm{~h}$ whereupon the mixture was brought to $\mathrm{pH} 6$ by adding $2 \mathrm{M}$ aqueous ammonia.

Gels M2 and M3 were synthesized from $\gamma-\mathrm{Al}_{2} \mathrm{O}_{3}$ ("aluminum oxide C" Degusa, mean primary particle size $13 \mathrm{~nm}$, BET $100 \mathrm{~m}^{2} / \mathrm{g}$ ) and $\gamma$-AlOOH, boehmite, ("Disperal" Condea Chemie, mean particle size $30-40 \mathrm{~nm}$, BET $188 \mathrm{~m}^{2} / \mathrm{g}$ ), respectively. The powders were peptized by adding $10 \mathrm{wt} . \%$
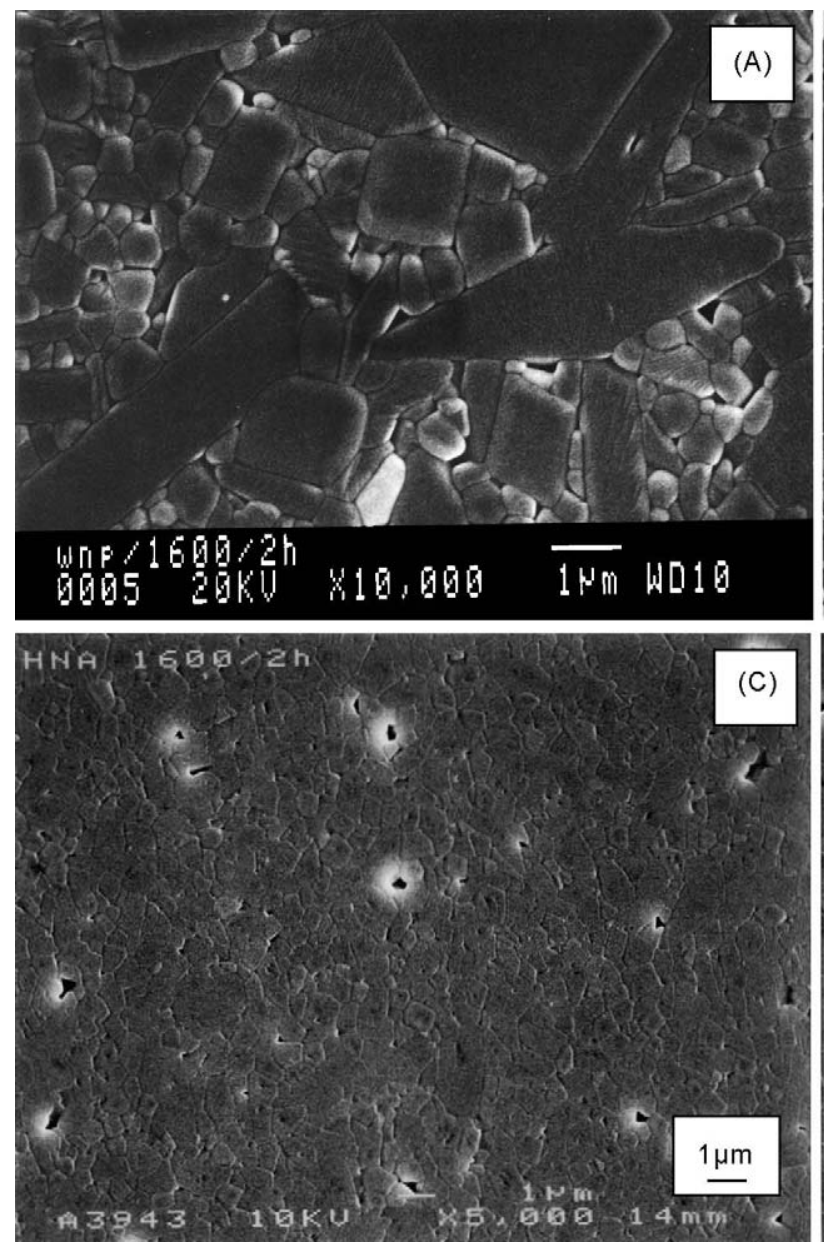

Table

Vickers hardness, HV, fracture toughness, $K_{\mathrm{IC}}$, and 4-point bending strength, with corresponding Weibull parameter, $\sigma$ and $m$, at ambient temperature of the samples sintered at $1600{ }^{\circ} \mathrm{C}$ for $2 \mathrm{~h}$

\begin{tabular}{llllc}
\hline Sample & HV $(\mathrm{GPa})$ & $K_{\mathrm{IC}}\left(\mathrm{MPa} \mathrm{m}^{1 / 2}\right)$ & $\sigma(\mathrm{MPa})$ & $\begin{array}{l}\text { Weibull } \\
\text { parameter }(\mathrm{m})\end{array}$ \\
\hline W & $13.5 \pm 0.2$ & $1.7 \pm 0.2$ & 283 & 8.9 \\
M1 & $13.5 \pm 0.2$ & $1.7 \pm 0.1$ & 261 & 13.6 \\
M2 & $12.5 \pm 0.3$ & $1.9 \pm 0.2$ & 204 & 12.1 \\
M3 & $12.9 \pm 0.3$ & $1.9 \pm 0.2$ & 246 & 4.4 \\
\hline
\end{tabular}

of $0.1 \mathrm{M}$ aqueous $\mathrm{HNO}_{3}$ solution. The suspensions were then stirred and refluxed for $24 \mathrm{~h}$ at $60^{\circ} \mathrm{C}$. Stoichiometric amount of $1 \mathrm{M}$ TEOS in ethanol was dropwise added and gelation was carried out by refluxion at $60{ }^{\circ} \mathrm{C}$. All prepared gels were further dried at $110^{\circ} \mathrm{C}$ for $72 \mathrm{~h}$ and stored in a vacuum desiccator. Dry gels were calcined at $700^{\circ} \mathrm{C}$ for $9 \mathrm{~h}$ to decompose organics and to remove volatiles. Calcined gels were wet ball milled in isopropanol using $\mathrm{ZrO}_{2}$ balls as milling media for $6 \mathrm{~h}$. After milling and drying of the precursor powders, rod-like green bodies performed by cold isostatic pressing $(200 \mathrm{MPa})$ were sintered at $1600^{\circ} \mathrm{C}$ for $2 \mathrm{~h}$.
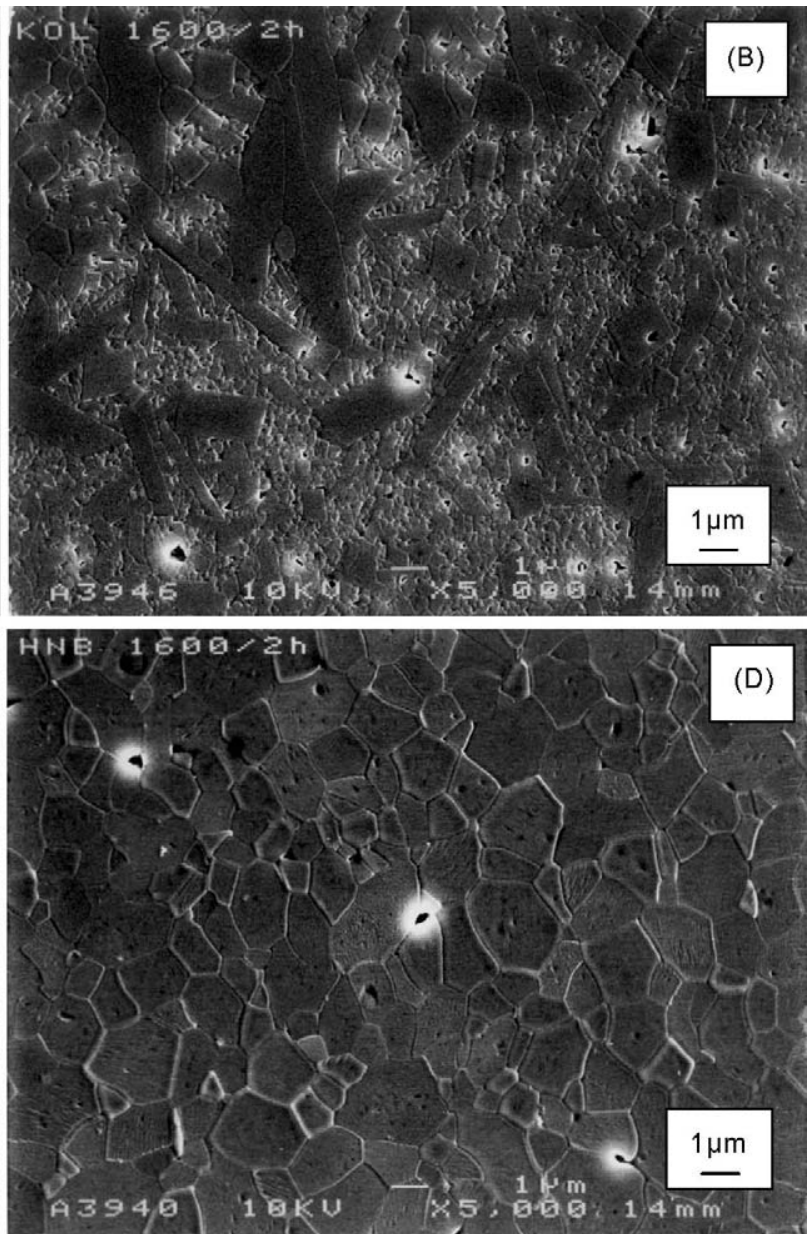

Fig. 1. SEM micrographs of mullite samples; (A) sample W; (B) sample M1; (C) sample M2; (D) sample M3. 


\subsection{Materials characterization}

Polished and thermally etched surfaces $\left(1500^{\circ} \mathrm{C}, 45 \mathrm{~min}\right)$ of sintered materials were analyzed by scanning electron microscopy (SEM, JEOL, JSM 6400F), and the average grain size was determined by the linear intercept method. For microstructural observations of samples after creep testing, micrographs on tension sides of the samples were analyzed. The same samples tested at $1400^{\circ} \mathrm{C}$ were subsequently fractured and the fracture surfaces near the tension and compression sides of the samples were analyzed. Transmission electron microscopy (TEM) equipped with energy dispersive X-ray analyzer EDX (JEOL $6400 \mathrm{~F}$ ), as well as, high resolving transmission electron microscopy (HRTEM) (CM200 FEG, Philips) equipped with an energy dispersive $X$-ray spectrometer (DX-4; EDAX) were used for analysis of specimens prepared by mechanical thinning, dimpling, $\mathrm{Ar}^{+}$ion milling and carbon coating.

The bending strength at ambient temperature was evaluated by a four-point bending test (spans 10 and $20 \mathrm{~mm}$ ) on bars $(3 \mathrm{~mm} \times 4 \mathrm{~mm} \times 25 \mathrm{~mm})$ polished by diamond slurry down to $1 \mu \mathrm{m}$. The hardness was measured by Vickers indentation with load of $10 \mathrm{~kg}$. The fracture toughness $\left(K_{\text {IC }}\right)$ was calculated according to Anstis et al. ${ }^{20}$ The creep resistance was measured in 4-point bending strength mode (spans 20 and $40 \mathrm{~mm}$ ) using polished samples with dimensions $3 \mathrm{~mm} \times 4 \mathrm{~mm} \times 45 \mathrm{~mm}$. The measurements were carried out at different stresses from 40 to $160 \mathrm{MPa}$ at the constant temperature $T=1400^{\circ} \mathrm{C}$, and at the constant stress of $100 \mathrm{MPa}$ from 1320 up to $1400^{\circ} \mathrm{C}$ (for sample M3 up to $1420^{\circ} \mathrm{C}$ ). The creep measurements at different stresses were performed stepwise on the same sample. The measurement at a higher stress was performed successively after the steady-state strain rate was attained. The measurement at the constant stress of $100 \mathrm{MPa}$ was performed by temperature jumps from one tested temperature to another. The samples were hold at the testing temperatures for $30 \mathrm{~min}$ before loading to reach the temperature stability. No stress correction was made for the change in cross-sectional area during the run. The experimental data were characterized in terms of steady-state creep rate according to the equation:

$\varepsilon^{*}=A \sigma^{n} \frac{1}{d^{p}} \exp \left(-\frac{Q}{R T}\right)$

where $\varepsilon^{*}$ is the steady-state creep rate in $\mathrm{s}^{-1}, \sigma$ is the stress in $\mathrm{MPa}, Q$ is the activation energy for creep deformation; $n$ is stress exponent, $d$ is grain size, $p$ is the grain size exponent, and $A$ is a material constant, which depends on microstructure. $T$ and $R$ have their usual meaning. Accordingly, the
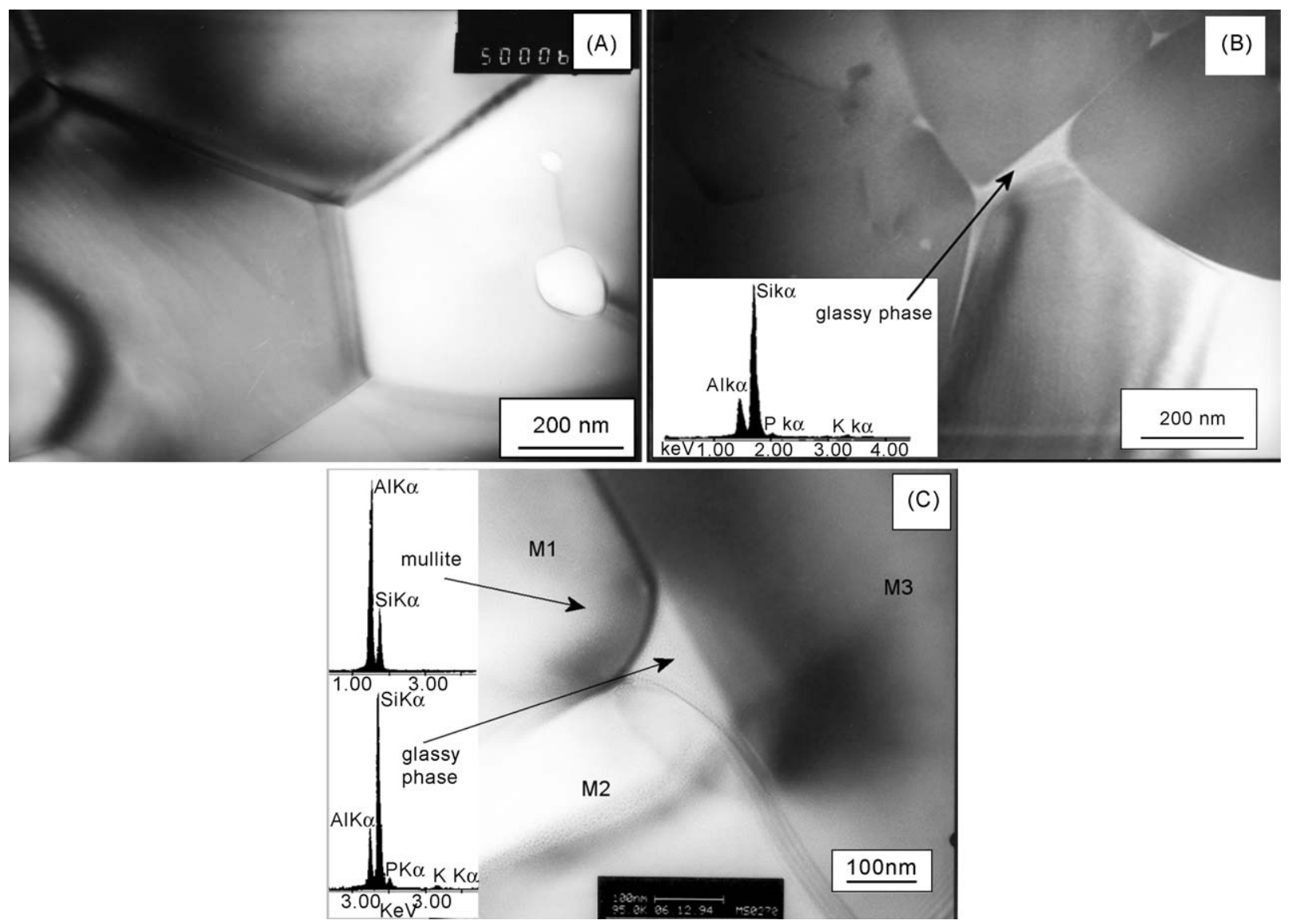

Fig. 2. TEM micrographs of studied samples: (A) sample M1; (B) sample M2, EDX spectrum of glassy phase given as overlay; (C) sample M3, EDX spectra of mullite grain and glassy phase in triple junction are given as insets. 
exponents $n$ and $p$ and the activation energy, $Q$, characterize the creep behavior of materials.

\section{Results}

The Vickers hardness, HV, fracture toughness, $K_{\mathrm{IC}}$, and 4-point bending strengths, $\sigma$, at ambient temperature for mul-
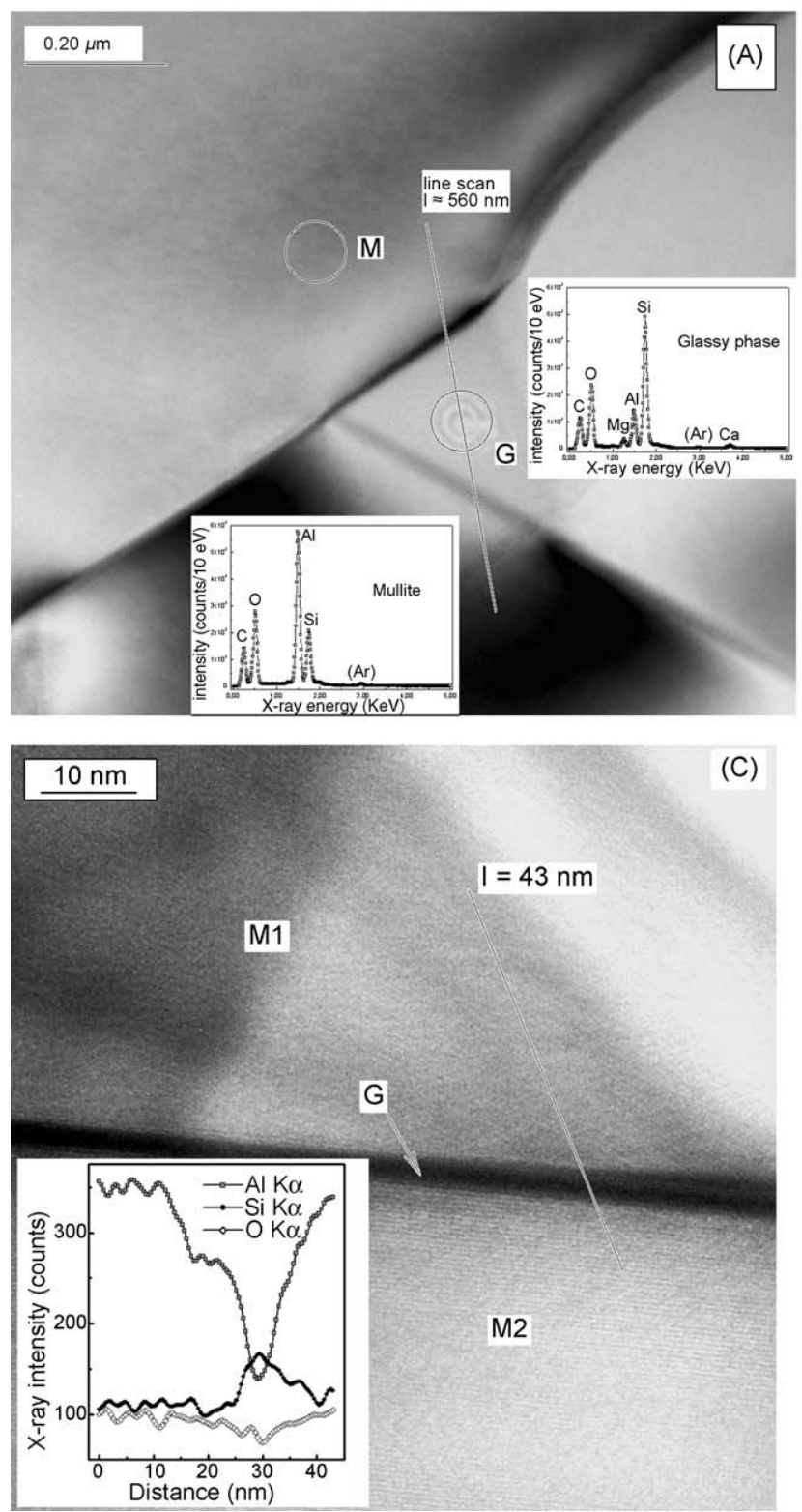

lite ceramics sintered at $1600{ }^{\circ} \mathrm{C}$ for $2 \mathrm{~h}$ are shown in Table 1 . Reported values of the results are the average of 10 measurements.

Representative microstructures of the studied samples are shown on SEM micrographs in Fig. 1. As shown on SEM micrographs, samples $\mathrm{W}$ and M1 are composed of two types of grains: elongated crystals (with longer axis about 4-10 $\mu \mathrm{m}$ for sample $\mathrm{W}$ and about 5-7 $\mu \mathrm{m}$ for specimen M1) are em-
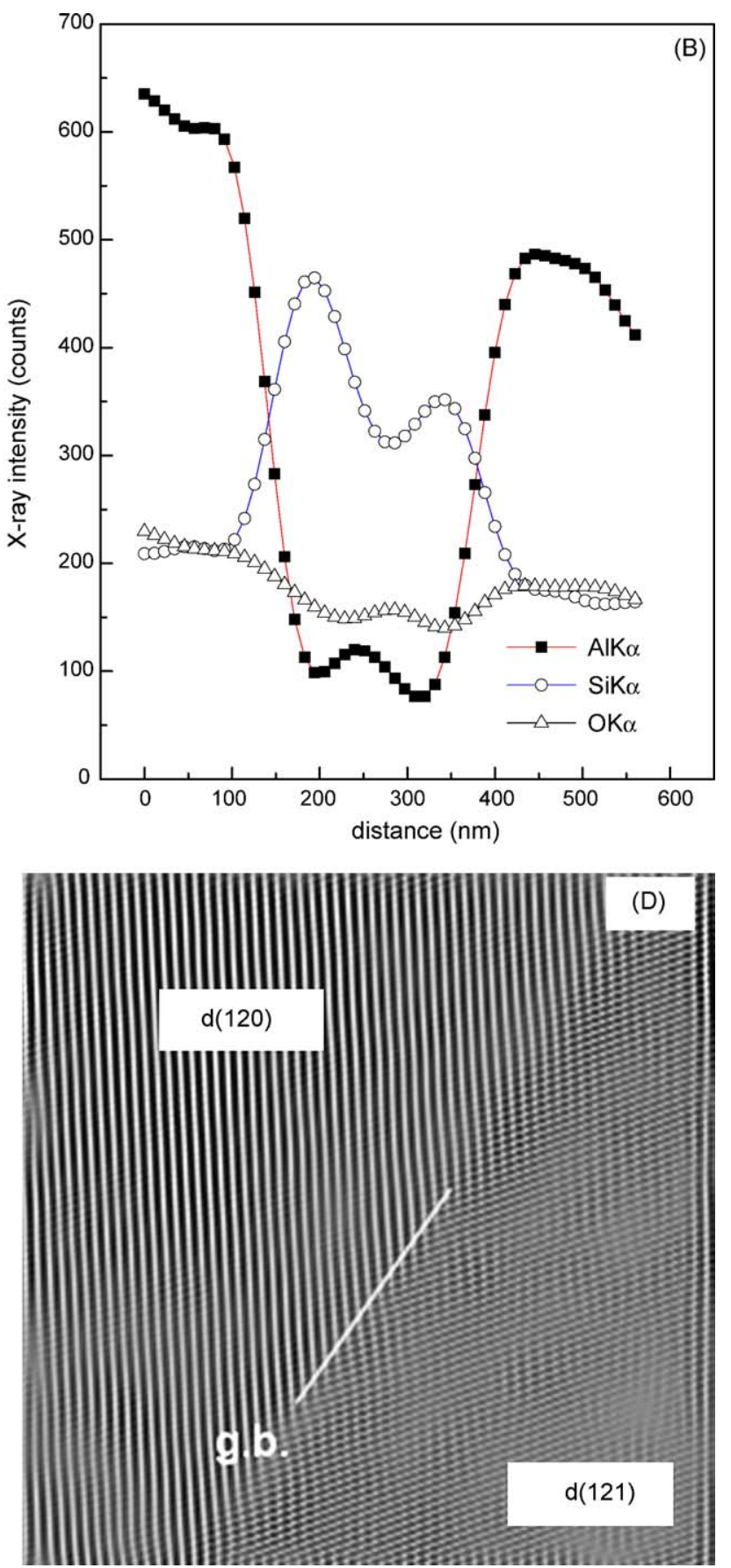

Fig. 3. (A) HRTEM micrograph of the sample $\mathrm{W}$ sintered at $1600^{\circ} \mathrm{C}$ for $2 \mathrm{~h}$. The insets give EDX analyses of glassy phase in marked circle $\mathrm{G}$ and mullite grain $\mathrm{M}$, respectively. (B) EDX line analysis across two mullite grains. The line along the analysis was performed is $560 \mathrm{~nm}$ long and is shown in (A). (C) HRTEM image of two mullite grains M1 and M2 and the glassy interphase (G). Inset (left lower corner) shows EDX line analysis across the grain boundary indicating the appearance of Al-containing silica glassy-phase at mullite interfaces. (D) HRTEM image of a mullite/mullite grain-boundary without glassy phase. 

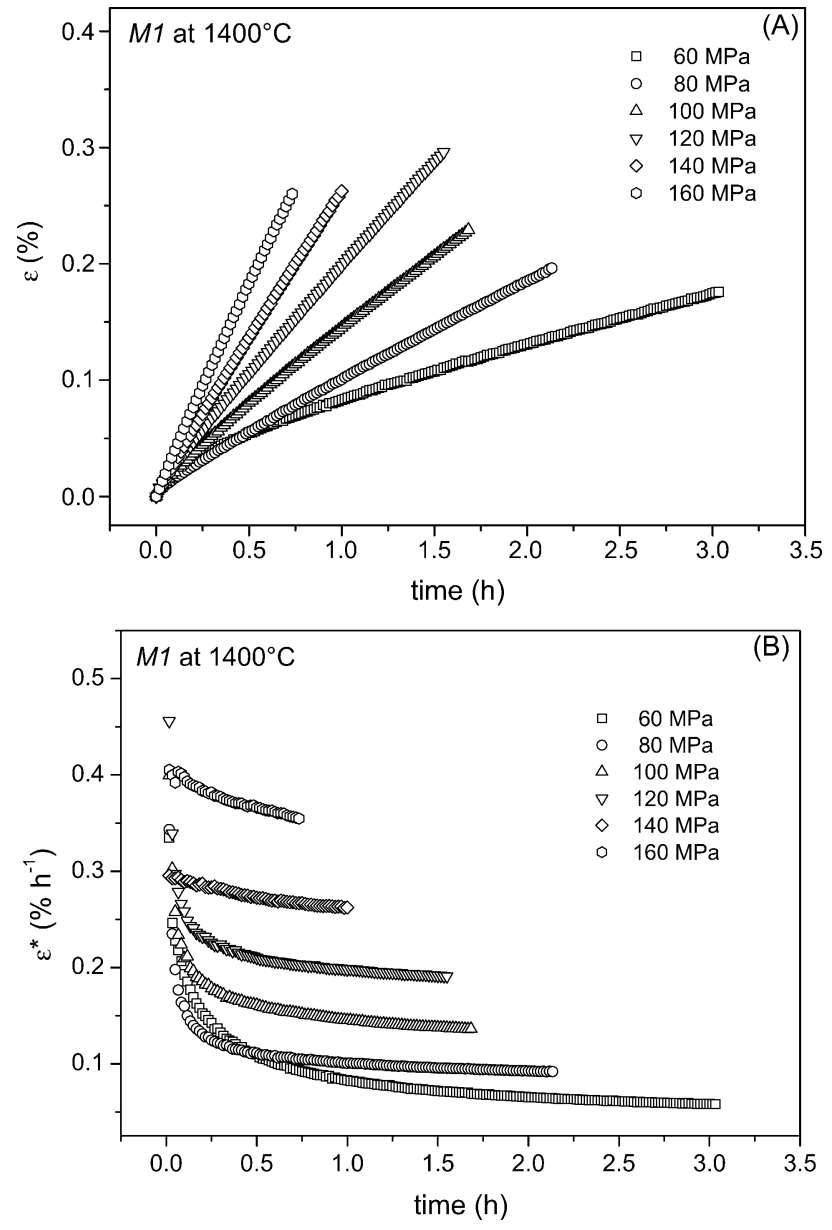

Fig. 4. Strain (A) and strain rate (B) vs. time for different stresses between 60 and $160 \mathrm{MPa}$ at $1400^{\circ} \mathrm{C}$ for sample M1.

bedded into a matrix of equiaxial grains much smaller than $1 \mu \mathrm{m}$, but the amount of the elongated grains in the sample M1 is greater than in sample $\mathrm{W}$. On the contrary, mullite grains in samples M2 and M3 are equiaxial with average size of 0.6 and $1.3 \mu \mathrm{m}$, respectively, and with monomodal grain size distributions. TEM micrographs and EDX analyses for samples M1, M2 and M3 are shown in Fig. 2. The image obtained by high resolved transmission electron microscopy (HRTEM) and the EDX line analysis across two mullite grains, as well as the point analysis of the glassy phase in triple junction for sample $\mathrm{W}$ is shown in Fig. 3. Typical strain versus time curve for M1 obtained at $1400{ }^{\circ} \mathrm{C}$ and at loads between 60 and $160 \mathrm{MPa}$, are shown in Fig. 4A, and the strain rate versus time plots in Fig. 4B. Strain curves and strain rate curves as a function of time for sample M3 are shown in Fig. 5A
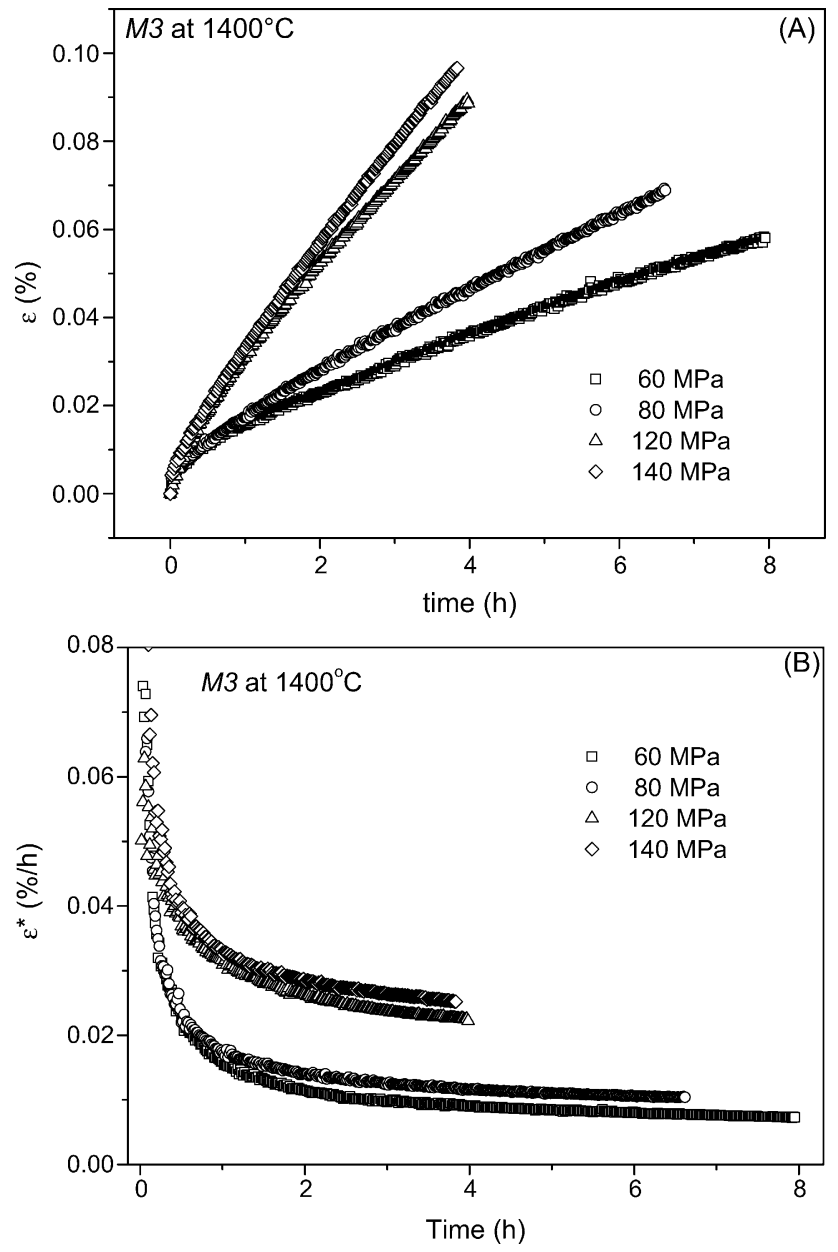

Fig. 5. Strain (A) and strain rate (B) vs. time for different stresses between 60 and $140 \mathrm{MPa}$ at $1400^{\circ} \mathrm{C}$ for sample M3.

and $\mathrm{B}$, respectively. Characteristic plots of strain rate versus stress for all studied materials at $1400^{\circ} \mathrm{C}$ are shown in Fig. 6 . From these plots the stress exponent, $n$, was determined. It should be pointed out that only the data at $40,60,80,100$ and $120 \mathrm{MPa}$ (for sample M3 also the result at $140 \mathrm{MPa}$ ) were taken into account for evaluation the stress exponent $n$, although the data at stresses of 140 and $160 \mathrm{MPa}$ are located on the same plot. The grain size-compensated strain rates versus stress $(p=3)$ for the samples are also given in Fig. 6 . Fig. 7 shows $\ln \varepsilon^{*}$ versus $1 / T$ plots obtained at the stress of $100 \mathrm{MPa}$, from which the activation energy for creep was evaluated. Stress exponent, $n$, and the activation energy, $Q$, are correlated with the mullite grain sizes in Table 2 .

Table 2

Grain size and grain size distribution, activation energy, $Q$, and stress exponent, $n$, at the stress of $100 \mathrm{MPa}$ and $T=1400^{\circ} \mathrm{C}$

\begin{tabular}{lllll}
\hline Sample & Grain size morphology & Mean grain size $(\mu \mathrm{m})$ & Activation energy, $Q(\mathrm{~kJ} / \mathrm{mol})$ & Stress exponent, $n$ \\
\hline W & Bimodal & $\sim 0.7$ (elongated grains: 4-10, equiaxial grains: $<1)$ & $563 \pm 33$ & $1.94 \pm 0.03$ \\
M1 & Bimodal & $\sim 0.5$ (elongated grains: 5-7, equiaxial grains: $<1)$ & $606 \pm 33$ & $2.05 \pm 0.01$ \\
M2 & Monomodal & 0.6 & $573 \pm 16$ & $1.69 \pm 0.04$ \\
M3 & Monomodal & 1.3 & $743 \pm 18$ & $1.75 \pm 0.04$ \\
\hline
\end{tabular}




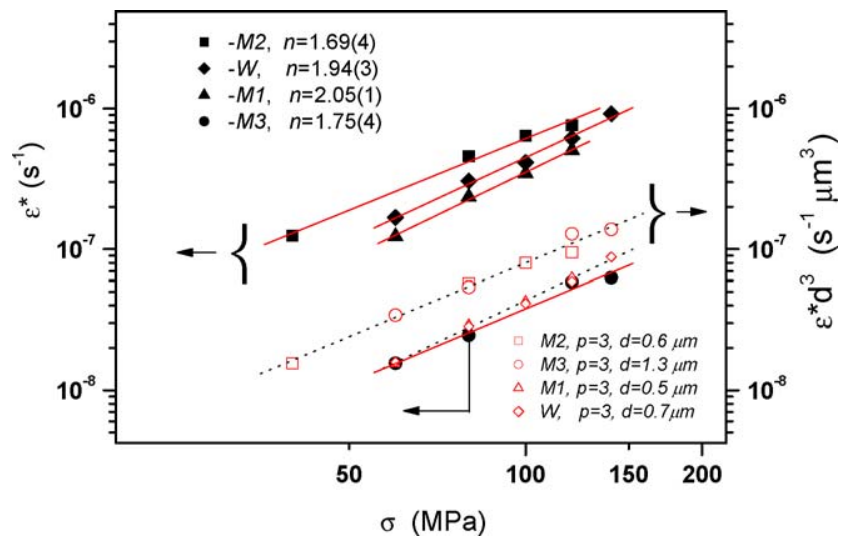

Fig. 6. Steady-state strain rate as a function of stresses at $1400^{\circ} \mathrm{C} . \mathrm{M} 2(\boldsymbol{\square})$; $\mathrm{W}(\diamond)$; M1 (\); and M3 (৩). Grain size-compensated strain rates vs. stress using $p=3$ : M2 $(\square)$; W $(\diamond)$; M1 (ム); M3 (○).

Specimens tested in creep have been analyzed by SEM. Fig. 8 shows the morphology of the tension surface of samples after creep at $1400{ }^{\circ} \mathrm{C}$ at two different loads (40 and $100 \mathrm{MPa}$ ). Fracture morphology of the same specimen near tension and compression surfaces, respectively, are shown in Fig. 9.

\section{Discussion}

\subsection{Microstructure and mechanical properties of un-crept samples}

Different microstructure of studied mullite ceramics seen on SEM micrographs (Fig. 1) is due to different alumina precursors used in preparation of studied samples, since the silica precursor (TEOS) was the same in all prepared gels. Using aluminum nitrate nonahydrate, $\left(\mathrm{Al}\left(\mathrm{NO}_{3}\right)_{3} \cdot 9 \mathrm{H}_{2} \mathrm{O}\right)$ bimodal grain size distribution of mullite grains is obtained, whereas by using transient alumina (added as $\gamma-\mathrm{Al}_{2} \mathrm{O}_{3}$ or in situ formed by boehmite decomposition) monomodal grain size distribution is achieved. If $\gamma-\mathrm{Al}_{2} \mathrm{O}_{3}$ is used as alumina

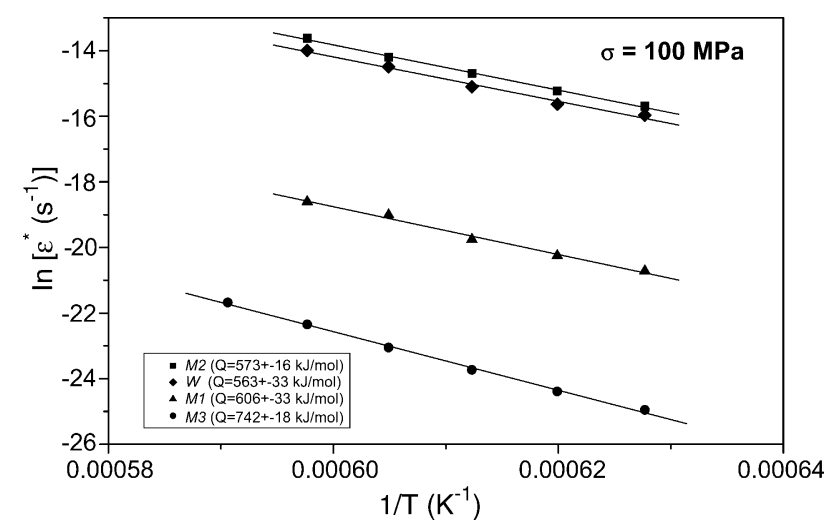

Fig. 7. Steady-state strain rates vs. reciprocal temperature for stress at

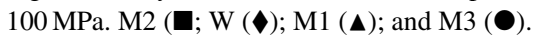

source much smaller mullite grains were obtained, whereas by reaction of boemite with TEOS more than twice greater mullite grains were produced. The microstructures seen with specimens $\mathrm{W}$ and M1 are typical for liquid flow sintering, ${ }^{21}$ whereas a solid state sintering is supposed for the equaxial mullite morphology (M2 and M3 samples). TEM and HRTEM micrographs and microanalyses, (Figs. 2 and 3), reveal the presence of glassy phase located at triple points and a thin film at grain boundaries. However, there are grain boundaries clean, without glassy phase (Fig. 3D). That is in accordance with Kleebe et al. ${ }^{22}$ who found that depending on the orientation of mullite grains, wetted and not wetted grain boundaries coexist. The present glassy phase is an aluminumcontaining silicate glassy phase, as shown by EDX analyses (EDX spectra in Figs. 2 and 3).

As can be seen in Table 1, the 4-point bending strength, $\sigma$, and corresponding Weibull parameter, $m$, the Vickers hardness, $\mathrm{HV}$, and fracture toughness, $K_{\mathrm{IC}}$, differentiate the samples with bimodal grain size distribution from those with monomodal grain size distribution. Samples with bimodal morphology (W and M1) are characterized by somewhat higher strength and Vickers hardness, and smaller fracture toughness than the samples with monomodal morphology (M2 and M3). Inside the latter, at the same number of tested specimens (10), the sample M3 (average grain size $=1.3 \mu \mathrm{m}$ ) shows a greater strength then the sample M2 (average grain size $=0.6 \mu \mathrm{m}$ ), but also a larger dissipation of results (smaller Weibull parameter). The microstructure and mechanical properties at room temperature clearly distinguish the studied samples into two groups with small but noticeable difference between them.

\subsection{Creep behavior}

There are great discrepancies among the proposed creep mechanisms for mullite in literature. Different stationary creep mechanisms; Nabarro-Herring ${ }^{23,24}$ Coble,${ }^{25}$ flow of hard grains in a viscous phase, ${ }^{16}$ or solution-precipitation in the presence of a viscous phase ${ }^{26}$ have been proposed for mullite..$^{2,4-6,8,9,14-16}$ Nabarro-Herring ${ }^{23,24}$ and Coble ${ }^{25}$ mechanisms or diffusional accommodating grain boundary sliding predict stress exponents close to 1 and grain size exponent, $p$, between 2 and 3 . When the diffusion takes place through the volume of grain $p=2$, and when the diffusion takes place in grain boundaries ${ }^{26} p=3$. Majority of authors propose the combination of two or more mechanisms. Dokko et al. ${ }^{14}$ suggested Nabarro-Herring mechanism accompanied by diffusional flow, and according to them, the glassy phase accounts for the higher creep rates and higher stress exponent than 1. Nabarro-Herring creep was thought to be dominant also by Ohira et al. ${ }^{9}$ Hynes and Doremus ${ }^{17}$ proposed the flow of mullite grains in a viscous glassy phase. According to Nixon et al. ${ }^{15}$ there are different creep mechanisms in mullite with and without glassy phase. They proposed that the creep of mullite containing small amounts of glassy phase is most likely controlled by grain boundary sliding (GBS) accommo- 

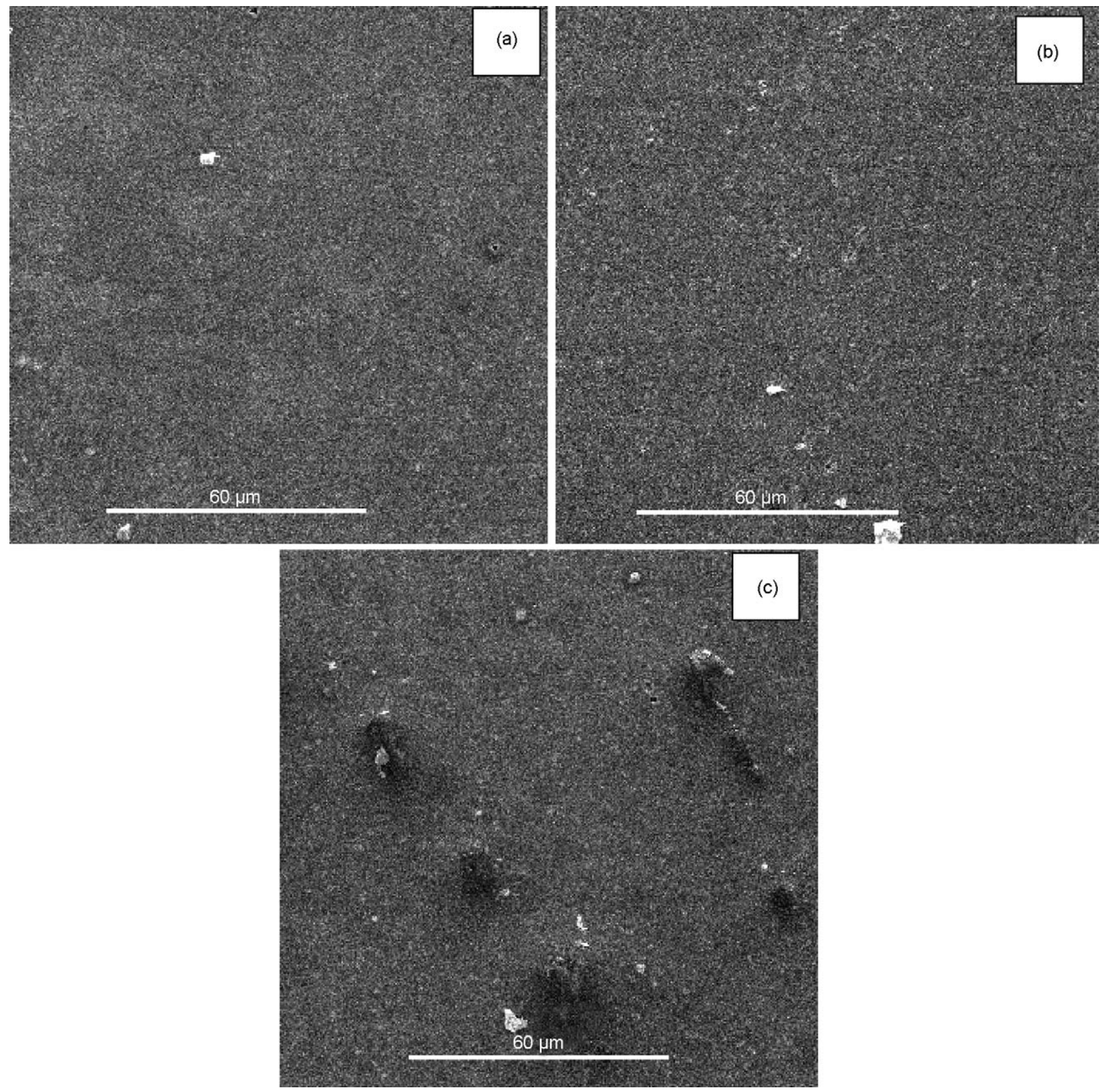

Fig. 8. Microstructure after creep tests. (a) SEM micrograph of tension surface for non-etched and un-crept sample W; (b) surface of sample after creep at $40 \mathrm{MPa}$ and $1400^{\circ} \mathrm{C}$; (c) surface of sample after creep at $100 \mathrm{MPa}$ and $1400^{\circ} \mathrm{C}$.

dated by diffusion in the glassy phase, but some viscous flow may also be present. At higher temperatures, these mechanisms were joined by cavitations along grain boundaries. On the contrary, in glassy phase free mullite, operating mechanism is GBS accommodated by lattice diffusion and cavitation. According to Torrecillas et al., ${ }^{11}$ the dominant creep mechanism is diffusion accommodated GBS, however, by stress-induced solution-precipitation, viscous flow of grains in amorphous phase-rich zones and self-diffusion of mullite can all contribute to the strain during creep. Rhanim et al. ${ }^{27}$ have proposed also GBS mechanism accommodated by a viscous creep. Studying the creep damage in mullite during the creep tests, Fernandez and Baudin, ${ }^{12}$ and Baudin and Villar ${ }^{13}$ propose stress enhanced dissolution of mullite grains at the stressed area even in samples containing no glassy phase before tests. Studying the creep behavior of mullite/alumina fibres, Deléglise et al. ${ }^{28}$ attributed the stress exponent $n=2$ to a higher viscosity of thin amorphous alumino-silicate intergranular glassy phase. De Arrelanno-López et al. ${ }^{19}$ believe that large variations in $Q$ values reported in literature and very different interpretations of creep mechanism could, at least partially, be related to grain morphology, as well as, to composition and location of the glassy phase.

It was stressed out ${ }^{11}$ that creep studies from different laboratories can lead to a significant scatter in results due to small differences in composition, microstructure and 

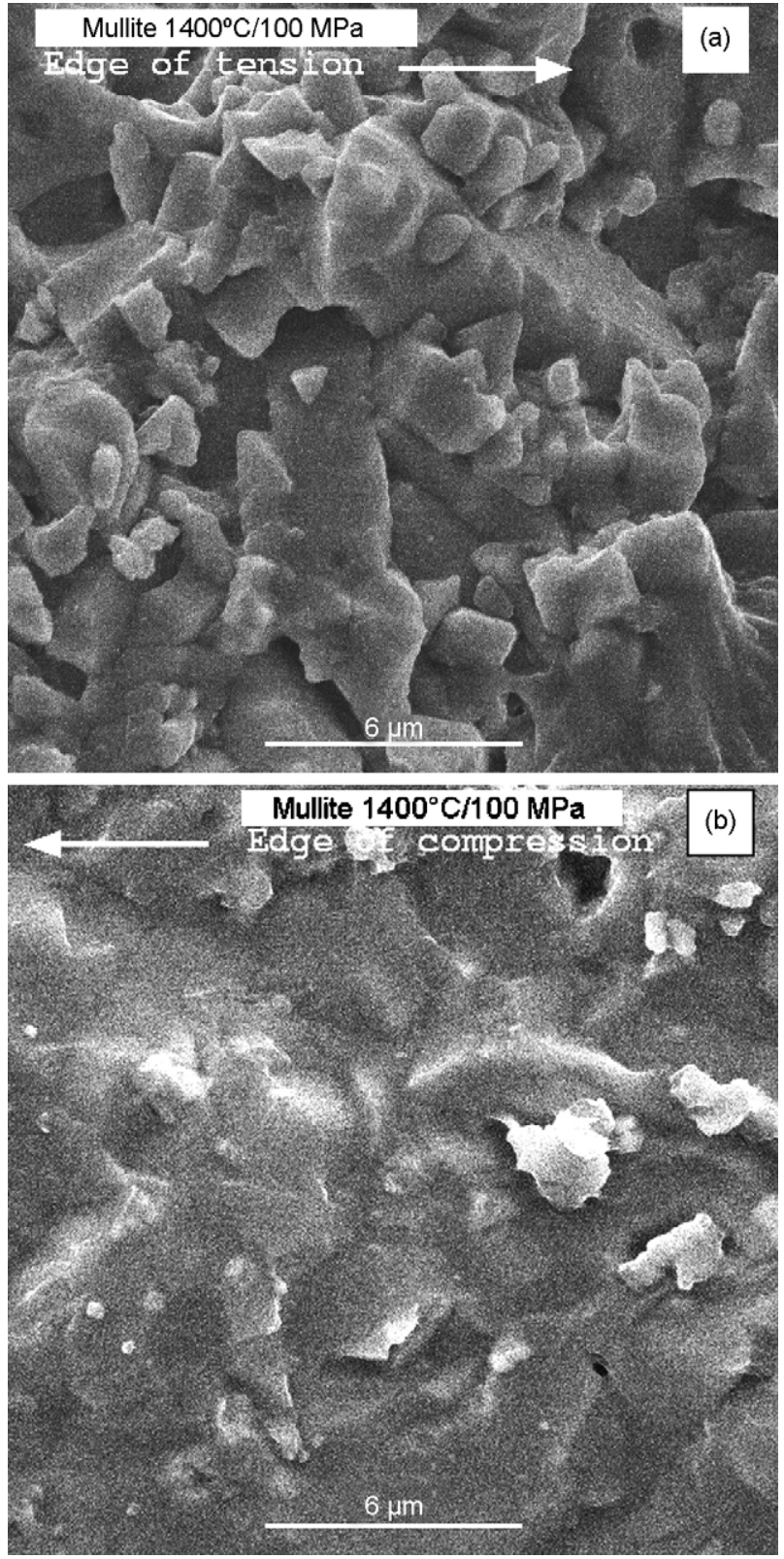

Fig. 9. SEM micrographs of fracture surface of sample W after creep at $1400^{\circ} \mathrm{C}$ and load of $100 \mathrm{MPa}$ : (a) near the tension side and (b) near the compression side of sample.

different testing procedures. Since in this work, for all four samples the same testing method was used and the gels are characterized by the same $\mathrm{Al} / \mathrm{Si}=3 / 1$ ratio (stoichiometric 3:2 mullite), creep results could be correlated only with microstructure, mullite grain size and the intergranular glassy phase in mullite ceramics. As seen in Fig. 6, the highest creep rate exhibited the sample with monomodal distributed grains in size of $0.6 \mu \mathrm{m}$ (sample M2). It is about one order of magnitude greater than that for sample with monomodal distributed grains in size of $1.3 \mu \mathrm{m}$ (sample M3). Creep rates for samples W and M1 (bimodal morphology) are somewhat smaller than that for sample M2. That is in accordance with the results of Dokko et al., ${ }^{14}$ who reported that the presence of elongated grains in a matrix of small equiaxial grains only slightly decreases the creep rate. Since the ratio of elongated and equiaxial grains in the samples studied in this work is much smaller than 1 , only a small decrease of creep rate in samples $\mathrm{W}$ and $\mathrm{M} 1$ in comparison to $\mathrm{M} 2$ was expected. The small difference between $\mathrm{W}$ and $\mathrm{M} 1$ is due to different amount and length of the elongated grains.

Torrecillas et al., ${ }^{11}$ observed that a scatter of strain rate values are significantly reduced when grain size exponent, $p$ [Eq. (1)], has been taken into evaluation. Therefore, they corrected the data cited by Lessing et al., ${ }^{2}$ Okamoto et al. ${ }^{8}$ and Nixon et al. ${ }^{15}$ multiplying the strain rate, $\varepsilon^{*}$, by $d^{p} ; p=2$ and 3 , respectively, and compared the obtained normalized $\varepsilon^{*} \times d^{p}-\sigma$ plots with their own results corrected on the same way. The scatter of the results was significantly reduced, especially using grain size exponent $p=3$. Using the same method and taking $p=3$, we obtained two $\varepsilon^{*} \times d^{p}-\sigma$ plots (hollow marks in Fig. 5); one $(n=1.74 \pm 0.08)$ for the both samples with monomodal and another $(n=1.98 \pm 0.05)$ for both samples with bimodal morphology independent on average grain size. Since the stress exponent, $n$, is a key indicator for identifying the rate controlling mechanisms, the same $n$ values for both samples with monomodal grain morphology, but with different grain sizes (Fig. 5), suggest the same creep mechanism. The same is valid for samples with bimodal grain morphology. Taking into consideration that more then one process is involved in grain boundary sliding, it could be proposed that all co-processes are not represented in the same extent at these two groups of samples. That means that the creep mechanism of monomodal morphology is somewhat different than that in samples with bimodal morphology.

The activation energy of $743 \pm 18 \mathrm{~kJ} / \mathrm{mol}$ for sample M3 (grains with mean size of $1.3 \mu \mathrm{m}$ ) matches with the value of $742 \mathrm{~kJ} / \mathrm{mol}$ obtained by Hynes et al. ${ }^{17}$ for mullite with $6 \mathrm{wt} . \%$ of glassy phase. However, for sample M2 with smaller equiaxial grain size $(0.6 \mu \mathrm{m})$ it is much smaller and yields $573 \pm 16 \mathrm{~kJ} / \mathrm{mol}$. Activation energy does not act as criteria for creep mechanisms, but it gives interesting details about creep if the activation energies are compared, especially for the ceramics possessing similar stress exponents, ${ }^{29}$ like are M3 and M2 samples. According to De Arrelanno-López et al. ${ }^{19}$ the smaller activation energy for M2 could be, at least partially, related to grain morphology.

There exists obvious difference in microstructure of samples before and after creep experiment, as shown on SEM micrographs in Fig. 8. Whereas the morphology of the tension surface before creep experiment and after creep test at $40 \mathrm{MPa}$ and $1400{ }^{\circ} \mathrm{C}$ are the same without any cracks (Fig. 8a and b), the morphology of the tension side of the same sample after the creep test at $100 \mathrm{MPa}$ and $1400^{\circ} \mathrm{C}$ showed damages accumulated by the development of intergranular microcracks (Fig. 8c). These results correlate with the results of Baudin and Villar ${ }^{13}$ who found that the damage observed in stoichiometrically mullite samples is directly related to creep testing. With higher load the damage is greater. SEM observations 
of fracture surfaces for the same samples near the compression and tension sides (Fig. 9) clearly revealed two zones in the samples. Intergranular fracture is predominant near the tension surface (Fig. 9a), while transgranular more planar fracture is predominant near the compression surface zone (Fig. 9b). This is in accordance to the results of Delèglise et al., ${ }^{28}$ who found that in mullite fibres the intergranular crack propagation is followed by an intragranular planar failure of the remaining section. These damages are created by the decomposition of mullite grains in the presence of liquid phase.

The discrepancies in creep mechanisms in mullites proposed by different authors have not been overcome yet. We agree with Baudin and Villar's statement ${ }^{13}$ that only exhaustive microstructural analysis of samples tested under a homogeneous stress state-pure compression or tension-could clarify the creep damage mechanisms in stoichiometric $3 \mathrm{Al}_{2} \mathrm{O}_{3} \cdot 2 \mathrm{SiO}_{2}$ mullites.

\section{Conclusion}

- Mullite samples with monomodal and bimodal grain size distribution were prepared using different alumina precursors. If aluminum nitrate nonahydrate is used as alumina component, specimen exhibited bimodally distributed grains. Elongated crystals are embedded into a matrix of polyhedral much smaller grains. On the contrary, if $\gamma-\mathrm{Al}_{2} \mathrm{O}_{3}$ or boehmite were used as alumina sources, the mullite grains are equiaxial with mean particle size of $0.6 \mu \mathrm{m}$ for the former and $1.3 \mu \mathrm{m}$ for the latter alumina precursor. Accordingly, the influence of alumina precursors was reflected on grain morphology and microstructure.

- The highest creep rate exhibited the sample with equiaxial grains of $0.6 \mu \mathrm{m}$ in size, which is about one order of magnitude greater than that for the sample with equiaxial grains of $1.3 \mu \mathrm{m}$ in size. The creep rates for both samples with bimodal morphology are positioned between.

- The creep data for the sample with monomodal distribution of particles in size $1.3 \mu \mathrm{m}$ with $n=1.75(2)$ and $Q=742 \pm 33 \mathrm{~kJ} / \mathrm{mol}$ are approaching to values observed by other authors. For sample with much smaller equiaxial grains $(0.6 \mu \mathrm{m}) n=1.64(4)$ and $Q=573 \pm 33 \mathrm{~kJ} / \mathrm{mol}$ have been achieved.

- Similar strain stress exponents and the same plot of grainsize compensated strain rate $\left(\varepsilon^{*} \times d^{3}\right)$ versus stress plot suggest the same mechanism(s) for both samples with monomodal morphology.

- The creep mechanism(s) for samples with bimodal morphology is in small extent but noticeable different from that with samples with monomodal morphology.

- SEM micrographs of fracture surfaces of samples after creep experiment have shown that intergranular fracture is predominant near the tension surface, while transgranular fracture is predominant near the compression surface zone.
- Only exhaustive microstructural analyses of samples with different morpholgy tested under pure compression or tension conditions could clarify the creep damage mechanisms in stoichiometric $3 \mathrm{Al}_{2} \mathrm{O}_{3} \cdot 2 \mathrm{SiO}_{2}$ mullites.

\section{References}

1. Schneider, H., Okada, K. and Pask, J. A., Mullite and Mullite Ceramics. Wiley, New York, 1994.

2. Lessing, P. A., Gordon, R. S. and Mazniyashi, K. S., Creep of polycrystalline mullite. J. Am. Ceram. Soc., 1975, 58(3-4), 149.

3. Penty, R. A. and Hasselman, D. P. H., Creep kinetics of high purity, ultra-fine grain polycrystalline mullite. Mater. Res. Bull., 1972, 7(10), 1117-1124.

4. Ashizuka, M., Okuno, T. and Kubota, Y., Creep of mullite ceramics. Yogyo Kyokaishi, 1989, 97(6), 662-668.

5. Ashizuka, M., Honda, T. and Kubota, Y., Effect of grain size on creep in mullite ceramics. Yogyo Kyokaishi, 1991, 99(4), 292-295.

6. Ohnishi, H., Maeda, K., Nakamura, T. and Kawanami, T., High temperature mechanical properties of mullite ceramics. In Ceram. Trans., vol. 6, Mullite and Mullite Matrix Composites, ed. S. Somiya, R. F. Davies and J. A. Pask. The Am. Ceram. Soc. Inc., Westerville, OH, 1990, pp. 605-612.

7. Jakus, K. and Wiederhorn, S. M., Creep deformation of ceramics in four-point bending. J. Am. Ceram. Soc., 1988, 71(10), 832-836.

8. Okamoto, H., Fukudome, H., Hayashi, K. and Nishikawa, T., Creep deformation of polycrystalline mullite. J. Eur. Ceram. Soc., 1990, 6(1), 161-168.

9. Ohira, H., Ismail, M. G. M. U., Yamamoto, Y., Akiba, T. and Somiya, S., Mechanical properties of high purity mullite at elevated temperatures. J. Eur. Ceram Soc., 1996, 16(2), 225-229.

10. Baudin, C., Osendi, M. I., Descamps, P. and Cambier, F., High temperature mechanical properties and creep behaviour of different mullites. In Key Engineering Materials, Euro Ceramics V, 132, ed. P. Abelard, M. Boussuge, Th. Chartier, G. Fantozzi, G. Lozes and A. Rousset. Trans. Tech. Publications, Switzerland, 1997, pp. 591-594.

11. Torrecillas, R., Calderón, J. M., Moya, J. S., Reece, M. J., Davies, C. K. L., Olagnon, C. and Fantozzi, G., Suitability of mullite for high temperature applications. J. Eur. Ceram. Soc., 1999, 19(11), 2519-2527.

12. Fernandez, E. and Baudín, C., Creep damage in different $3 \mathrm{Al}_{2} \mathrm{O}_{3} \cdot 2 \mathrm{SiO}_{2}$ mullites tested in 4-point bending. J. Eur. Ceram. Soc., 2001, 21(12), 2243-2251.

13. Baudin, C. and Villar, M. P., Microstructural and microchemical analysis of the creep damage in mullite tested in flexure. J. Eur. Ceram. Soc., 2002, 22(14-15), 2647-2655.

14. Dokko, P. C., Pask, J. A. and Mazdiyasni, K. S., High-temperature mechanical properties of mullite under compression. J. Am. Ceram. Soc., 1977, 60(3-4), 150-155.

15. Nixon, R. D., Chevacharoenkul, S., Davis, D. F. and Tiegs, T. N., Creep of hot-pressed $\mathrm{SiC}$ whisker reinforced mullite. In Ceram. Trans., vol. 6, Mullite and Mullite Matrix Composites, ed. S. Somiya, R. F. Davies and J. A. Pask. The Am. Ceram. Soc. Inc., Westerville, OH, 1990, pp. 579-603.

16. Calderón-Moreno, J. M. and Torrecillas, R., Hightemperature creep of polycrystalline mullite. In Key Engineering Materials Euro Ceramics V, 132, ed. P. Abelard, M. Boussuge, Th. Chartier, G. Fantozzi, G. Lozes and A. Rousset. Trans. Tech. Publications, Switzerland, 1997, pp. 587-590.

17. Hynes, A. P. and Doremus, R. H., High-temperature compressive creep of polycrystalline mullite. J. Am. Ceram. Soc., 1991, 74(10), 2469-2475.

18. Tkalcec, E., Nass, R., Krajewski, T., Rein, R. and Schmidt, H., Microstructure and mechanical properties of slip-cast sol-gel derived mullite ceramics. J. Eur. Ceram. Soc., 1998, 18(8), 1089-1099. 
19. De Arellano-López, A. R., Meléndez-Martínez, J. J., Cruse, T. A., Koritala, R. E., Routbort, J. L. and Goretta, K. C., Compressive creep of mullite containing $\mathrm{Y}_{2} \mathrm{O}_{3}$. Acta Mater, 2002, 50(17), 43254338.

20. Anstis, G. R., Chanticul, P., Lawn, B. R. and Marshall, D. B., A critical evaluation of indentation techniques for measuring fracture toughness: I. Direct crack measurements. J. Am. Ceram. Soc., 1981, 64, 533-538.

21. Kanka, B. and Schneider, H., Sintering mechanisms and microstructural development of coprecipitated mullite. J. Mater. Sci., 1994, 29, 1239-1249.

22. Kleebe, H. J., Hilz, G. and Ziegler, G., Transmission Electron Microscopy and Electron Energy Loss Spectroscopy characterization of glassy phase in sol-gel derived mullite. J. Am. Ceram. Soc., 1996, 79(10), 2592-2600.

23. Nabarro, F. R. N., Steady state diffusional creep. Phil. Mag., 1967, 16, 231-317.
24. Herring, C., Diffusional viscosity of a polycrystalline solid. J. Appl. Phys., 1950, 21(5), 437-445.

25. Coble, R. L. N., A model for boundary diffusion controlled creep in polycrystalline materials. J. Appl. Phys., 1963, 34(6), 1679-1682.

26. Raj, R., Tsai, R. L., Wang, J. G. and Chyung, C. K., Superplastic flow in ceramics enchanced by a liquid phase. In Deformation of Ceramic Materials II, ed. R. E. Tressler and R. C. Bradt. Plenum Press, New York, 1984, pp. 353-378.

27. Rhanim, H., Olagnon, C., Fantozzi, G. and Torrecillas, R., Experimental characterisation of High-temperature Creep Resistance of Mullite. Ceram. Int., 1997, 23, 497-507.

28. Deléglise, F., Berger, M. H. and Bunsell, A. R., Microstructural evolution under load and high temperature deformation mechanisms of a mullite/alumina fibre. J. Eur. Ceram. Soc., 2002, 22(9-10), $1501-1512$.

29. Lin, M. T., Shi, J. L., Jiang, D. Y., Ruan, M. L. and Lai, T. R., Mater. Sci. Eng. A, 2001, 300, 61 